\title{
Intravesical Solution Dosage Form
}

National Cancer Institute

\section{Source}

National Cancer Institute. Intravesical Solution Dosage Form. NCI Thesaurus. Code C149620.

Liquid preparation consisting of an aqueous solution intended for intravesical use by means of a suitable applicator. 